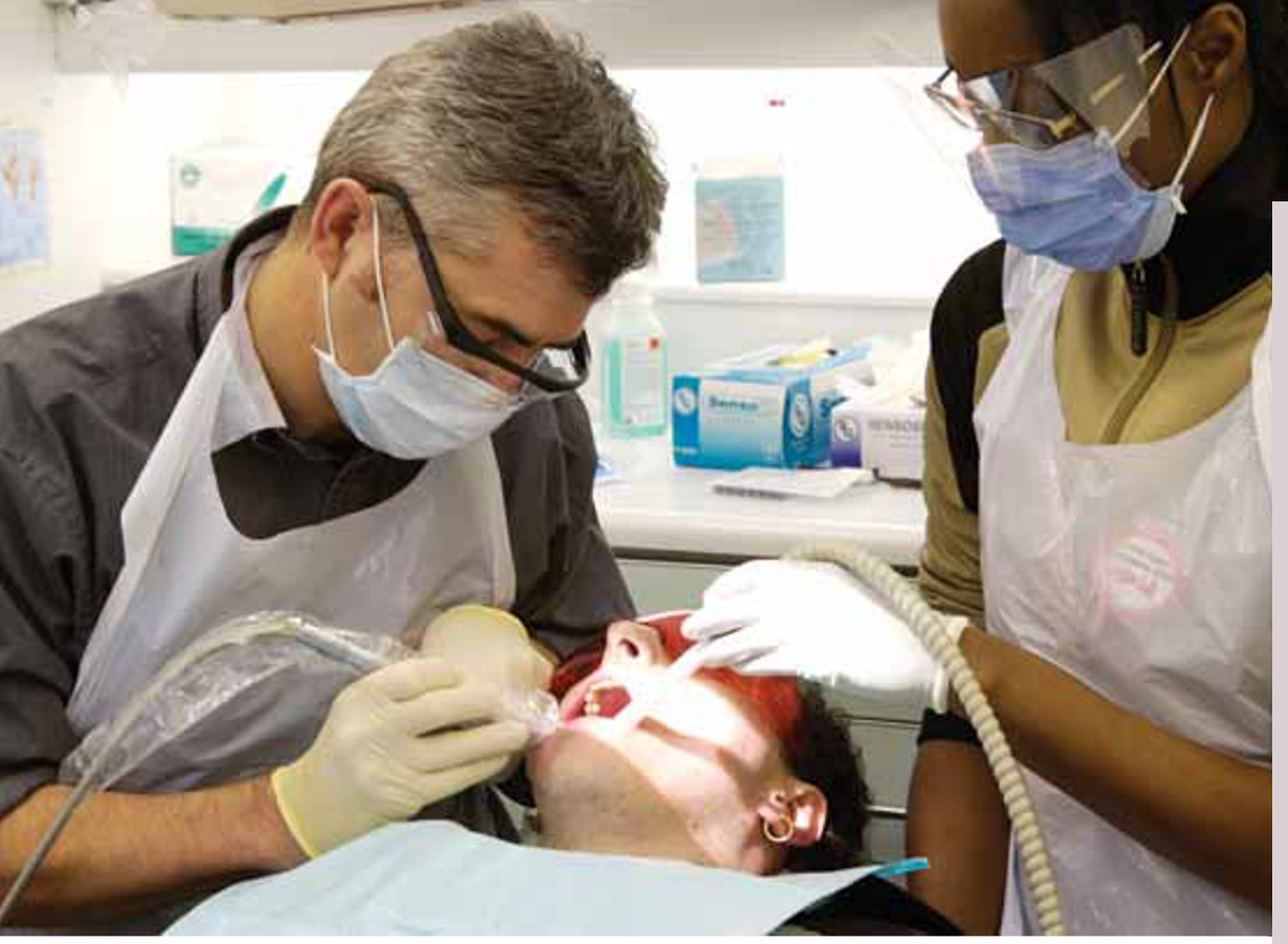

Dental nurses and hygienists are urgently wanted to volunteer to work over Christmas to help homeless people in London as part of Crisis Christmas - from 23-30 December.

The Crisis Christmas dental service, which is also appealing for dentists, relies on qualified volunteers to provide check-ups, scale and polishes, fillings and extractions under local anaesthetic. Crisis will set up nine temporary centres across the capital over Christmas and hopes to build on the success of last year when 120 patients received dental care.

Leslie Murphy, chief executive of Crisis,

DENTISTS SHOULD PRESCRIBE NICOTINE THERAPY

Dentists should be allowed to prescribe nicotine replacement therapy and all members of the dental team should be trained to give smoking cessation advice, a new report has recommended.

Beyond smoking kills: protecting children, reducing inequalities, published in October to mark the tenth anniversary of the Government's white paper on smoking, points out that one in seven 15-yearolds regularly smokes and that one in six mothers smokes through pregnancy.

It calls for the number of the NHS Smoking Helpline to be included on all cigarette packets and for the abolition of prescription charges on nicotine replacement therapy.

The report, funded by Action on Smoking and Health (ASH), Cancer Research UK and the British Heart Foundation, is endorsed by which started in 1971 with 20 volunteers in a derelict church, said: 'Crisis Christmas would not be possible without the help of the 6,500 volunteers who generously donate their time and skills. So if you know anyone with relevant skills and experience please spread the word.' Shifts run from 8.30 am to $6 \mathrm{pm}$ and volunteer dental professionals will be expected to do at least two.

To find out more telephone 0207426 3874, email volunteering@crisis.org.uk or apply online at www.crisis.org.uk/ volunteering.

\section{DH TO INVESTIGATE FREQUENT CHECK-UPS}

The Department of Health (DH) is to investigate dentists who it believes are 'gaming the system' and recalling healthy patients for check ups to trigger extra payments.

In a statement last month, the DH said: 'It is clear from new data available to PCTs that many patients are being seen every six months or so. This effectively prevents new patients from getting access to NHS dentistry. NICE guidance says that adults with healthy teeth do not need to go to their dentist as frequently as every six months if there is no clinical need. It is a contractual requirement for dentist to apply the NICE guidance.'

The Dental Health Services Research Unit at Dundee University is planning a four-year study examining the effectiveness of different recall intervals for check-ups. the British Dental Association and the British sionals' undergraduate training and ongoing development. 'All health professionals should advice to smokers, including an offer of treatment and referral to specialist services,' it says. 